\title{
Front-line of genome editing technology for animal cell engineering
}

\author{
Tetsushi Sakuma \\ From 24th European Society for Animal Cell Technology (ESACT) Meeting: C2P2: Cells, Culture, Patients, Products \\ Barcelona, Spain. 31 May - 3 June 2015
}

\section{Background}

Genome editing technology heralds a new era for animal cell engineering. Programmable site-specific nucleases, such as transcription activator-like effector nucleases (TALENs) and clustered regularly-interspaced short palindromic repeats (CRISPR)/Cas9, enable to induce DNA double-strand breaks (DSBs) at any desired genomic loci, resulting in efficient gene knockout and knockin in broad range of cultured cells [1].

As for gene knock-in, homologous recombination (HR)-assisted method has generally been used for spontaneous or programmable nuclease-mediated donor DNA integration. It enables precise gene knock-in, but the labor for constructing targeting vector with long homology arms and limited applicability due to the lower HR activity have been technical hurdles to utilize this method.

\section{Materials and methods}

Our group has so far developed various systems in genome editing field, such as the Platinum Gate TALEN system for constructing highly-active Platinum TALENs [2,3] and the Multiplex CRISPR/Cas9 Assembly System for creating all-in-one CRISPR/Cas9 vector enabling highlyefficient multiplex genome editing in cells and animals $[4,5]$. Recently, along with the use of these systems, our group newly established the PITCh (Precise Integration into Target Chromosome) system, which facilitates convenient gene knock-in in cultured cells and organisms [6,7].

\section{Results and conclusions}

Our PITCh system utilizes an alternative DSB repair pathway, microhomology-mediated end-joining (MMEJ),

Correspondence: tetsushi-sakuma@hiroshima-u.ac.jp Department of Mathematical and Life Sciences, Graduate School of Science, Hiroshima University, 1-3-1 Kagamiyama, Higashi-Hiroshima, Hiroshima 7398526, Japan which enables easy, efficient and precise gene knock-in without relying on HR. Using the PITCh system, we have successfully shown gene knock-in in human cells, silkworms, zebrafish, and frogs [6,7]. Importantly, there had been no report of successful gene knock-in in frogs because of low HR frequency.

Along with some modifications after the publication of the original paper, the PITCh system now enables backbone-free, direction-oriented, and non-mutagenic integration of large gene cassette in various cells and organisms with simple construction of the unique donor vector, termed PITCh vector (Figure 1).We believe that this method will provide technical and practical contributions to a wide range of researchers interested in TALEN- or CRISPR/Cas9-based gene knock-in in a variety of cells and organisms.

Published: 14 December 2015

\section{References}

1. Sakuma T, Woltjen K: Nuclease-mediated genome editing: At the frontline of functional genomics technology. Dev Growth Differ 2014, 56:2-13.

2. Sakuma T, Ochiai H, Kaneko T, Mashimo T, Tokumasu D, Sakane Y, et al: Repeating pattern of non-RVD variations in DNA-binding modules enhancesTALEN activity. Sci Rep 2013, 3:3379.

3. Sakuma T, Yamamoto T: Engineering customized TALENs using the Platinum GateTALEN Kit. Methods Mol Biol 2015.

4. Sakuma T, Nishikawa A, Kume S, Chayama K, Yamamoto T: Multiplexgenome engineering in human cells using all-in-one CRISPR/ Cas9 vectorsystem. Sci Rep 2014, 4:5400.

5. Nakagawa Y, Sakuma T, Sakamoto T, Ohmuraya M, Nakagata N, Yamamoto T: Production of knockout mice by DNA microinjection of various CRISPR/Cas9 vectors into freeze-thawed fertilized oocytes. BMC Biotechnol 2015, 15:33.

6. Nakade S, Tsubota T, Sakane Y, Kume S, Sakamoto N, Obara M, et al: Microhomology-mediated end-joining-dependent integration of donor DNA in cells and animals using TALENs and CRISPR/Cas9. Nat Commun 2014, 5:5560.

7. Hisano Y, Sakuma T, Nakade S, Ohga R, Ota S, Okamoto H, et al: Precise inframe integration of exogenous DNA mediated by CRISPR/Cas9 system in zebrafish. Sci Rep 2015, 5:8841. 


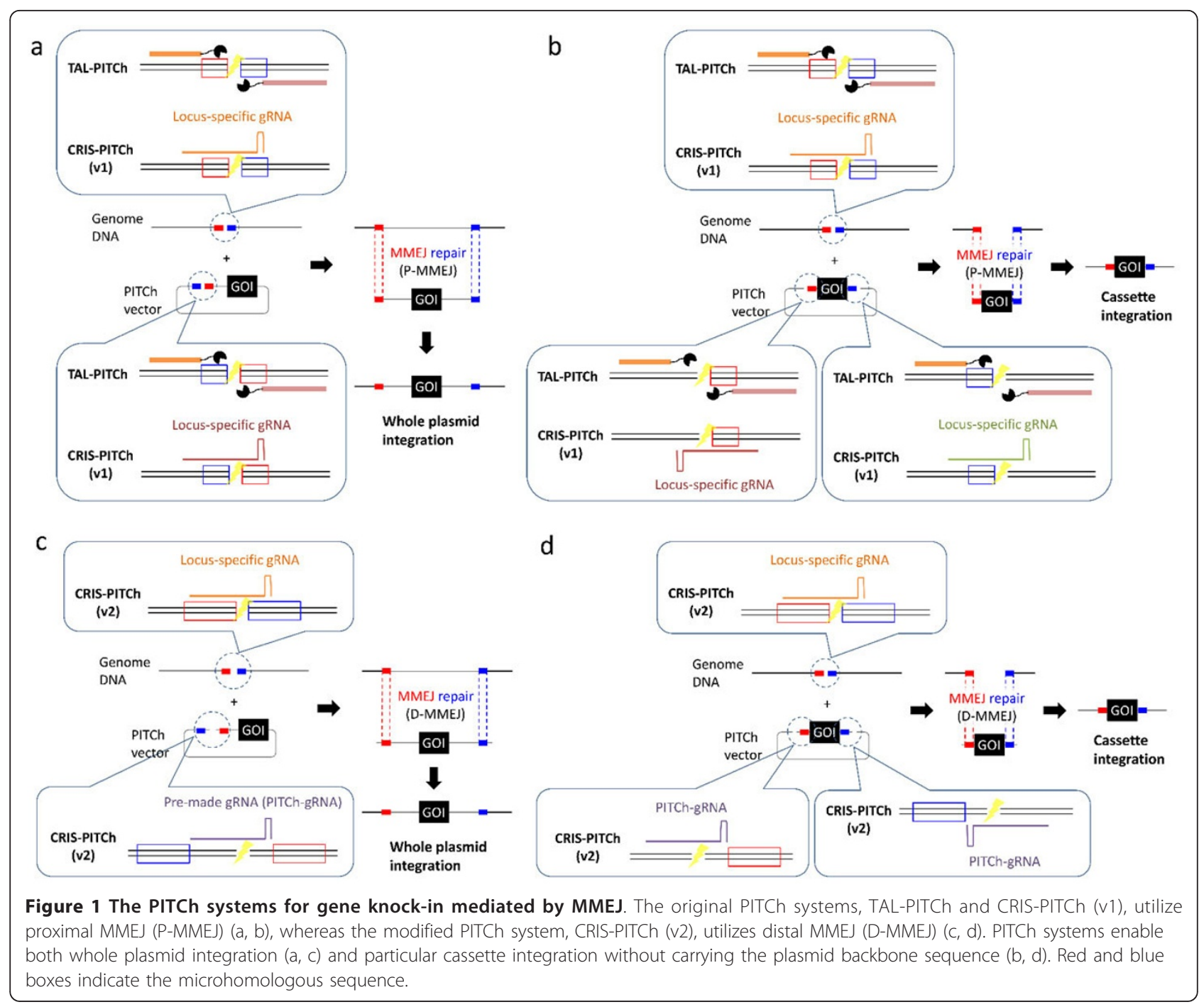

doi:10.1186/1753-6561-9-S9-01

Cite this article as: Sakuma: Front-line of genome editing technology

for animal cell engineering. BMC Proceedings 2015 9(Suppl 9):01.

Submit your next manuscript to BioMed Central and take full advantage of:

- Convenient online submission

- Thorough peer review

- No space constraints or color figure charges

- Immediate publication on acceptance

- Inclusion in PubMed, CAS, Scopus and Google Scholar

- Research which is freely available for redistribution

Submit your manuscript at www.biomedcentral.com/submit 